\title{
NOTA SOBRE EL CORPUS ELEGÍACO HELENÍSTICO: FANOCLES
}

\author{
Rafael J. Gallé Cejudo* \\ Universidad de Cádiz \\ rafael.galle@uca.es
}

\begin{abstract}
RESUMEN
El pasaje de Ps.-Prob., in Verg. B. 2.23 podría constituir un testimonio de transmisión indirecta de la obra de Alejandro de Etolia (frg. 21 Magnelli) y de Fanocles. En esta nota crítica se aportan nuevos argumentos a favor de esta autoría, lo que, en el caso de Fanocles supondría una importante aportación a un corpus relativamente exiguo.
\end{abstract}

Palabras Clave: Elegía helenística, crítica textual, Alejandro de Etolia, Fanocles.

\section{NOTE ON HELLENISTIC ELEGIAC CORPUS: PHANOCLES}

\section{ABSTRACT}

The passage of Ps.-Prob., in Verg. B. 2.23 could be an indirect transmitted testimony of the work of Alexander Aetolus (frg. 21 Magnelli) and Phanocles. This critical note provides new arguments in favour of this authorship, which, in the case of Phanocles, would entail a significant contribution to a relatively exiguous corpus.

KEYWORDs: Hellenistic elegy, textual criticism, Alexander Aetolus, Phanocles.

La revisión editorial de los textos clásicos ha de ser entendida como un proceso vivo, porque la labor de crítica textual sobre un texto no termina con la edición: un texto editado será siempre susceptible de ser revisado y de ser mejorado. Y uno de los aspectos más complejos y delicados de ese proceso, aparte de la revisión del aparato crítico y naturalmente del texto, es la relectura de los testimonia y, si procede, la reinterpretación del corpus textual, directo e indirecto, de cada autor. Pues bien, el objetivo de esta breve nota es ofrecer nuevos argumentos en apoyo de la autoría fanoclea de una cita indirecta contenida en un pasaje conflictivo del comentario de Ps.-Probo a las Bucólicas de Virgilio (2.23). En este pasaje podría estar citándose a Alejandro de Etolia (de hecho es recogido en las últimas ediciones de Magnelli o Lightfoot como frg. $21 d u b$.) y quizá también a Fanocles, con lo que de alguna forma podría contribuir así a incrementar, aunque solo sea de forma indirecta y casi simbólica, el corpus textual de los llamados, un tanto condescendientemente, poetas elegíacos helenísticos menores. El pasaje en cuestión es el siguiente: 
Ps.-Prob., in Verg. B. 2.23 (3.2, p. 329 Thilo-Hagen)

«Canto, quae solitus, si quando armenta uocabat

Amphion Dircaeus»

Amphionem et Zethum Euripides et apud nos Pacuuius Iouis ex Antiopa Nyctei ait natos. <Amphionem autem> cantando potuisse armenta uocare testantur Thebae, quas Apollonius in Argonautis a fratribus ante dictis muro esse clausas ait, sed Zethus humeris saxa contulit operi, Amphion cantu euocauit, si quidem sensus animalium facilius quam saxa uincuntur. †Panocus $\dagger$ et Alexander lyram a Mercurio muneri datam dicunt, quod primus $\dagger$ Euianaram liberauit $\dagger$.

Ps.-Probo, Comentario a Virgilio, Bucólicas 2.23

«Canto lo que solía, cuando llamaba a su rebaño,

Anfión Dirceo»

De Anfión y Zeto, Eurípides y, entre nuestros escritores, Pacuvio dicen que son hijos de Zeus y Antíope, la hija de Nicteo. <Y de que Anfión> con su canto podía convocar los rebaños da testimonio Tebas, que Apolonio ${ }^{1}$ en los Argonautas dice que fue circunvalada por una muralla por los hermanos antes citados; pero Zeto llevó las piedras a la obra en sus hombros, mientras que Anfión las hizo venir con su canto, si verdaderamente es más fácil vencer los sentidos de los animales que a las piedras. $†$ Panoco $\dagger$ y Alejandro dicen que la lira le fue concedida como regalo por Mercurio, porque fue el primero †liberar a Evianara $\dagger$.

Sobre el Alexander citado en la penúltima línea nada se sabe con certeza, pero si se conjetura que bajo el ininteligible Panocus al que acompaña está encubierto en verdad un Phanocles original, las probabilidades de que sea el Etolio crecen considerablemente: al Etolo lo adscriben Schneidewin (perteneciente a la elegía Apolo), Radtke (de la elegía Musas), Meineke (251) y Powell (17 CA, apelando a la cita del monte Aracinto del texto virgiliano y la cercanía de Pleurón, patria del Etolo); a Alejandro Polihístor lo adscribe Wilamowitz (con la oposición de Jacoby, FGrHist. IIIa, 311-312, y el apoyo de Gioseffi, 1991: 201-204); a Alejandro de Efeso lo adscribe West; y a Alejandro Mindio lo atribuye Lehnus. Pero, como bien señala Magnelli, todas las hipótesis son posibles, pero ninguna incontrovertible ${ }^{2}$. Ahora bien, si, como

* Agradecimiento expreso al MINECO por su apoyo al Proyecto FFI2017-85015-P «Las migraciones temáticas entre la prosa y el verso: el papel referencial de la elegía helenística». Agradezco también a los responsables de Fortunatae haberme permitido participar con esta breve nota en este merecido homenaje a Ángel Martínez Fernández. Estas reflexiones surgen al calor de la nueva edición de los poetas elegíacos helenísticos que muy pronto verá la luz en la prestigiosa colección de autores griegos y latinos Alma Mater del CSIC.

${ }^{1}$ Las referencias de los autores citados son las siguientes: en el caso de Eurípides (podría hacer referencia a la Antíope), Test. IV b (Kannicht); para Pacuvio, frg. 1 Ribbeck (también de una Antíope); y para Apolonio de Rodas, Argonáuticas 1.735-741.

${ }^{2}$ Cf. Magnelli, 1999: 264-267, para las diferentes propuestas de adscripción y la bibliografía específica en cada caso. 
se ha indicado, hay serios problemas para identificar al Alejandro citado, no menor es la aporía en el caso de Panocus de la penúltima línea: la forma transmitida por los códices (Panocus) fue ya corregida en Panyas(s)is en la editio princeps de Egnatius (Venecia 1507) y por ello ha sido incluido el fragmento (siempre entre los dubia) en las ediciones de este poeta épico (Matthews frg. 31 = 32 Bernabé = 4 Davies); Dübner interpreta que la forma ha de ser corregida en Phanodicus (FGrHist. 397, frg. 7 dub.); Wernicke (col. 1945) y Powell (ad loc.) se decantan por Pacuvius, el segundo argumentando que no está documentado que Fanocles tratara este tema (¿̨?), mientras que Pacuvio sí lo hizo en su Antiopa, pero Pacuvio es citado unas líneas antes por lo que es muy improbable que el copista errara en este nombre; Gioseffi (1991: 200, n. 115, siguiendo de cerca a Cazzaniga, SIFC 32, 1960, 141-142) prefiere leer Parthenius, mientras que Schneidewin (RhM 4, 1846, 143), Jacoby (FGrHist. 397, frg. 7) y Hagen (ad loc.) se decantan por Phanocles, dando por válida la conjetura de que el Alejandro citado es el Etolo y relacionando contextualmente ambos elegíacos helenísticos. Hay, no obstante, otras dos hipótesis argumentativas que podrían avalar esta propuesta, ambas basadas, he de reconocerlo, en relaciones muy circunstanciales: la vinculación etiológica que con este episodio también tiene la poetisa Mero, circunscrita como los anteriores al ámbito elegíaco helenístico, y la temática homoerótica en la que Filóstrato contextualiza el episodio mitológico.

Que la lira fue un regalo de Hermes a Anfión es una tradición documentada desde temprano (Eumel., frg. 13 Bernabé; E., Antiop. frg. 48.90-92 Kambitsis; Moero, frg. 6 CA; Hor., Carm. 3.11.1-2; Apollod. 3.5.7; Philostr., Im. 1.10.1; Myth. Vat. II 92, p. 167 Kulcsár; Sch. E. Ph. [hyp.-Sch.] 115.11) y de hecho hay una rama de la tradición que transmite que Anfión era hijo de Hermes (cf. Sch. Stat. Theb. $1.10)^{3}$. Sin embargo, la última parte de la frase (Euianaram liberauit) no parece tener sentido. Ahora bien, desde que Meineke acertó a relacionar este pasaje con el citado

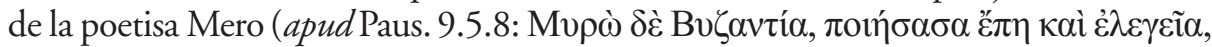

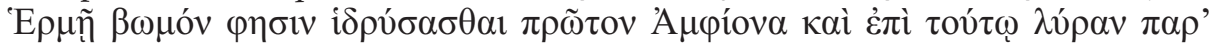

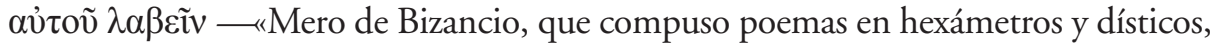
sostiene que el primero en erigir un altar a Hermes fue Anfión y que por eso recibió de él la lira»—) y propuso la corrección ei aram dedicauerit o ei in ara libauerit, la crítica coincide en que la idea podría estar cerca de «porque fue el primero en dedicarle un altar» $\mathrm{o}$ "porque fue el primero en hacerle ofrendas en el altar» ${ }^{4}$. Nótese por otra parte que Mero (o más bien Pausanias) emplean el verbo i $\delta \rho v ́ \sigma \alpha \sigma \theta \alpha \iota$ para 'erigir',

${ }^{3}$ Hay, no obstante, otras variantes mucho menos extendidas: a) que la lira fue regalo de Apolo en Diosc.Hist., FGrHist 594, frg. 12 (ap. Sch. A.R. 1.740, 62.10-15 Wendel) o en Eust. Od. 11.259 (1.412 Stallbaum); b) que la lira fue regalo de las Musas en Pherecyd., FGrHist 3, frg. 41a, o Armen., FGrHist 378, frg. 2 (ambos también apud Sch. A.R. 1.740, 62.10-15 Wendel); y c) que la lira fue regalo de Zeus en Eust. Od. 11.259.

${ }^{4}$ Ya así desde Stoll, 1884: 312. 
que en latín podría corresponder a leuo y de ahí que la corrección del pasaje pueda pasar por leuauerit (ei aram leuauerit). En cuanto a la forma transmitida liberauit la más conocida 'liberación' en la que está envuelto este personaje es la de su madre Dirce, pero poco o nada tiene que ver con Hermes. Interesante es, finalmente, la propuesta de Schneidewin que retrotrae el verbo a una forma de $\lambda \hat{\omega} \omega$ en griego, ya que los juegos de palabras entre $\lambda \hat{\omega} \omega$ y $\lambda \hat{\rho} \rho \alpha$ son frecuentes en época tardía 5 .

Creo, no obstante, que, en este contexto argumentativo, no se ha prestado suficiente atención al pasaje de la descripción de Anfión en las Imágenes de Filóstrato (1.10.3):

Philostr., Im. 1.10.3

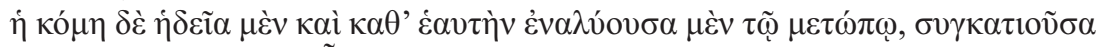

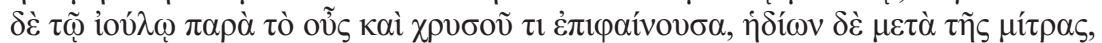

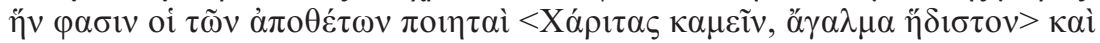

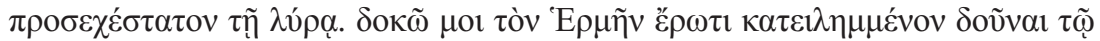

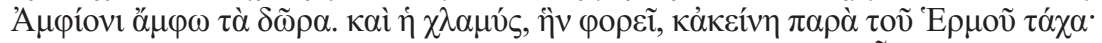

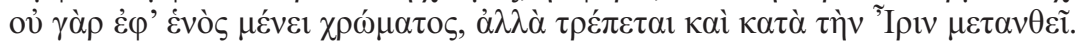

Filóstrato, Imágenes 1.10.3

Su cabello es una delicia: le ondea de suyo por la frente, se le junta al bozo al caerle junto a las orejas y está dotado de cierto brillo dorado; pero más delicioso aun está con la cinta, aquella que los poetas de versos mistéricos dicen que «Las Gracias recamaron, el más lindo adorno» y el más apropiado para la lira. En mi opinión, Hermes hizo ambos regalos a Anfión completamente arrebatado de amor. Y la clámide que lleva, también esa, debe proceder de Hermes, pues no permanece de un solo color, sino que se atornasola y va adquiriendo las tonalidades del arco iris.

En esta écfrasis se desvelan dos detalles muy interesantes. Asegura el sofista que Hermes regaló la lira y la diadema a Anfión, porque estaba perdidamente enamorado de él (ह̌ $\rho \omega \tau \imath ~ \kappa \alpha \tau \varepsilon \imath \lambda \eta \mu \mu \varepsilon ́ v o v)$ y además sostiene que en la obra de ciertos «poetas

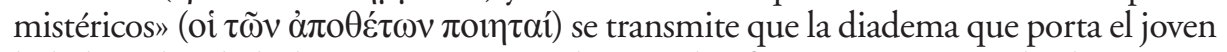
la habían bordado las Gracias. Sin embargo, el sofista está convencido de que, no solo esta cinta, sino también la prodigiosa clámide tornasolada fueron regalos de Hermes motivados por ese amor apasionado. Así pues, en contra de lo que la crítica sostenía, hay, aparte de la versión de Mero e incluso contradictoria con ella, otra fuente antigua en la que se motiva el regalo ${ }^{6}$. Y, además, el hecho de que haya un contexto de amor

${ }^{5}$ Las principales propuestas y conjeturas sobre este pasaje son las siguientes: Euianaram liberauit $\mathrm{AV}: \operatorname{Eian}^{n} \operatorname{ara}(m) \mathrm{M}:$ Eyianaram dicit $\mathrm{P}:$ Cynaram ed. princ. : Io Inachiam Lloyd-Jones : ei aram dedicauerit vel $e i$ in ara libauerit Meineke $:$ exta ei in ara libauerit Schneidewin $:$ exta ei in ara litauerit Powell.

${ }^{6}$ Cf. Magnelli, 1999: 266: «In base a Moero, che sola precisa la motivazione del dono ...». Nótese que ni siquera Stoll, Wermicke, Beyer o las fuentes antiguas citadas en n. 3 (Dioscórides, Ferécides, Arménidas, Eustacio o los Escolios a Apolonio de Rodas) recogen esta relación homoerótica. 
homosexual, aparentemente gratuito, pero claramente constatado por Filóstrato, hace que la atribución a Fanocles gane enteros. No en vano Fanocles es el غ̇

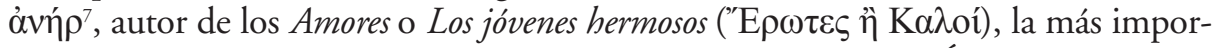
tante elegía catalógica de temática homoerótica masculina de la Época Helenística.

Por último, y a modo de addenda, si la hipótesis que aquí propongo fuera válida, quizá habría que plantear en términos muy diferentes (no tan apegados al texto de Mero y más coincidente con el de Filóstrato) el locus uexatus antes citado †Euianaram liberauitt, pues bajo la lectura del códice $\mathrm{M}^{8}$ Eian ${ }^{n}$ ara podría subyacer un original quod primus ei amore laboranit - «porque fue el primero en sufrir de amores por él»e incluso con genitivo objetivo (eius encubierto quizá en Euianaram de $\mathrm{A} \mathrm{y}^{9}$ ) en lugar de dativo commodi ei; a saber: quod primus eius amore laborauit ${ }^{\circ}$. Sobre la expresión laboro con este mismo ablativo instrumental de causa amore, cf. Séneca, Contr. 2.2.4.16: domum amore mutuo laborantem; Séneca (Iun.), QN 4a, pr. 2.3: amore nostri laboramus, Apuleyo, Met. 5.25.23: amore nimio laboras; Pomponio Porphyrio, Comm. 1.17, lema 19-20: amore laborantis; ibid. 1.27, lema 18-19: quanta laboras Charybdi (en contexto erótico).

\section{REFERENCIAS BIBLIOGRÁFICAS}

Albiani, M. G. (2000): «Moiro», Brill's New Pauly 8: col. 344.

AleXander, K. (1988): A Stylistic Commentary on Phanocles and Related Texts, Ámsterdam.

BACH, N. (1829): Philetae Coi, Hermesianactis Colophonii atque Phanoclis reliquiae, Halle.

BEYER, R. (1910): Fabulae Graecae quatenus quave aetate puerorum amore commutatae sint, Diss. Inaug., Weida.

Blumenthal, A. v. (1938): «Phanokles», RE 19.2: cols. 1781-1783 [Stuttgart].

Di Gregorio, L. (2012): «Merò (?) e Niceneto: due sconociuti?», Aevum 86.1: 63-154 (esp. 63-115).

GEFFCKEN, J. (1932): «Moiro», RE 15.2: cols. 2512-2513 [Stuttgart].

Giarratano, C. (1905): Hermesianactis fragmenta, Milán-Palermo-Nápoles.

Gioseffi, M. (1991): Studi sul commento a Virgilio dello Pseudo-Probo, Florencia.

Lightfoot, J. L. (2009): Hellenistic Collection: Philitas, Alexander of Aetolia, Hermesianax, Euphorion, Parthenius, Cambridge (MA) - Londres.

Magnelli, E. (1999): Alexandri Aetoli testimonia et fragmenta. Introduzione, edizione critica, traduzione e commento, Firenze.

${ }^{7}$ Así llama a Fanocles Plutarco en sus Charlas de sobremesa 4.5.3 (Obras morales 671B-C).

${ }^{8}$ Códice Monacensis Lat. 755.

` V: códice Vaticanus Lat. 2930 (s. XV²); y A: Excerpta de Policiano en una edición de Virgilio (Roma 1471) conservada en la Biblioteca Nacional de Francia Rés. g. Y c. 236.

${ }^{10}$ Agradezco públicamente a mi colega latinista Joaquín Navarro López esta segunda sugerencia. 
Matthews, V. J. (1974): Panyassis of Halikarnassos, Laiden.

Powell, I. U. (1925): Collectanea Alexandrina, Oxford.

Thilo, G. - Hagen, H. (1902): Servii Grammatici qui feruntur in Vergilii Carmina Commentarii vol. III.2, Leipzig.

STOLl, H. W. (1884): «Amphion (1)», en W. H. RosCHER, Ausfïhrliches Lexikon der griechischen und römischen Mythologie, Leipzig, pp. 308-316.

WERMICKE, K. (1894): «Amphion (1)», RE 1: cols. 1944-1948 [Stuttgart].

WheELock, F. M. (1935): «The Manuscript Tradition of Probus», HSCP 46: 85-153. 